\title{
INNOVACIÓN EN EL MERCADO TURÍSTICO: EXPERIENCIAS EN ARTE URBANO
}

\author{
Montse Crespi Vallbona* \\ Universitat de Barcelona \\ https://orcid.org/0000-0001-8267-4786 \\ Oscar Mascarilla Miró** \\ Universitat de Barcelona \\ https://orcid.org/0000-0002-3952-3517
}

\section{RESUMEN}

El turismo es una de las actividades que más encarecidamente precisa de la innovación y la creatividad para mantenerse constantemente en auge. Las tendencias actuales de la demanda exigen experiencias activas, que generen emociones, esten repletas de contenido, tengan dosis de placer. El arte urbano siempre presente en los espacios públicos de las ciudades, emerge como una propuesta innovadora, atendiendo a su capacidad de provocación e interacción con el peatón espectador. Barcelona es el actual laboratorio turístico en el que se lleva a cabo la denominada Pinacoteca a Cel Obert, una galeria de arte abierta que ocupa el espacio público de la ciudad, con 24 obras pictóricas clásicas en el sí de calles comerciales, en las puertas de sus establecimientos. El análisis cualitativo de la información recopilada en la encuesta a 150 visitantes y las entrevistas a los stakeholders del proyecto, conduce a determinar que esta galeria de arte urbano y su itinerario ofrecen una satisfactoria experiencia turística, repleta de emociones y vivencias.

Palabras clave: turismo experiencial; gobernanza; sostenibilidad; arte urbano; Barcelona.

Fecha de recepción: 22 de octubre de 2019.

Fecha de aceptación: 9 de junio de 2020.

* Departamento de Empresa. Facultad de Economía y Empresa. Universitat de Barcelona. Diagonal 690. 08034 BARCELONA (España).E-mail: mcrespi@ub.edu

** Departamento de Economía. Facultad de Economía y Empresa. Universitat de Barcelona. Diagonal 690. 08034 BARCELONA (España). E-mail: omascarilla@ub.edu 


\title{
Innovation in tourism market: experiences in street art
}

\begin{abstract}
Tourism is one of the activities that most urgently requires innovation and creativity to keep its constantly booming. The current demand tendencies require active experiences, that generate emotions, experience content, doses of pleasure. The permanent presence of street art in public spaces emerge now as an innovative proposal due to its capacity of provocation and interaction with the pedestrian observar. Barcelona is the present tourism lab where the Pinacoteca a Cel Obert is implemented, an open gallery in the public space of the city, with 24 classic paintings into the street, on the business doors. Cualitative analysis of collected data in the survey to 150 visitors and the interviews to the project stakeholders, lead to conclude that this street art gallery and its itinerary offer a satisfactory tourist activity, pleint of emotions and experiences.
\end{abstract}

Keywords: experience tourism; governance; sustainability; street art; Barcelona.

\section{INTRODUCCIÓN}

Los destinos turísticos consolidados precisan de una gobernanza que vele constantemente por la competitividad de la marca, la captación del interés del turista y por la complacencia de la comunidad residente. Lidiar con estos retos y por ello ofrecer experiencias turísticas de calidad y hacer de los destinos enclaves turísticos sostenibles son el cometido de las administraciones locales a día de hoy. Habitualmente, los espacios centrales de las ciudades turísticas son los que primeramente aglutinan estas manifestaciones: reúnen los recursos patrimoniales de interés del visitante y transforman la vida de sus vecinos. Diversificar los atractivos para expandir los flujos turísticos al resto de áreas menos centrales de la ciudad es una de las estrategias. Ofrecer experiencias innovadoras y memorables a los visitantes es otra prioridad. Conseguir la colaboración y entusiasmo de la ciudadanía en estas acciones es esencial para su continuidad y sostenibilidad. El caso de estudio que se presenta ilustra esta tríade. Por ello, el objetivo de esta investigación es observar como una ciudad turística consolidad como Barcelona, se reinventa constantemente para mantener su posicionamiento de marca, creando nuevas experiencias y descentralizando su atractividad para descongestionar su centro histórico. Pinacoteca a Cel Obert es una experiencia de street art, con características diferenciadas de la concepción estricta de arte urbano, puesto que escenifica obras clásicas de la historia del arte y por tanto se aleja de su carácter inicialmente reivindicativo. Se implementa en un barrio de poca atractividad turística y con el objetivo de dinamizar comercial, social y culturalmente la zona para sus vecinos. Las redes establecidas entre los diferentes entes involucrados en la creación y desarrollo del proyecto son la clave de su éxito. Esta gobernanza compartida y participada desde la administración pública, la empresa privada y la ciudadanía responden a este modelo sostenible de los destinos turísticos que buscan conciliar los intereses de los turistas con la cotidianedad de los ciudadanos. Por último, se focaliza el análisis en los componentes esenciales que deben centrar el diseño de 
cualquier visita turística guiada para asegurar una experiencia satisfactoria holística. Éstos son: participación, hedonismo, conocimiento, identidad local, degustación y nostalgia. Metodológicamente, a partir de datos secundarios y primarios obtenidos a partir de las entrevistas a los responsables de la conducción y desarrollo del proyecto, y la información que aporta la encuesta a los 150 participantes del itinerario guiado por el barrio, se concluye que las experiencias turísticas planificadas deben aportar siempre una dosis de valor añadido y memorabilidad para su satisfacción final.

\section{EL CONTEXTO TURÍSTICO DE LOS DESTINOS URBANOS}

Los debates actuales entorno a las ciudades turísticas consolidadas se centran en la apropiación, desnaturalización y banalización de los espacios públicos por parte de unos usuarios temporales que fluyen por los centros urbanos, segregados y tematizados, debidamente planificados y promocionados, ahuyentando la calidad del paseo y del vivir cotidiano de los residentes locales (Harvey, 1994; Hannigan, 1998; Fainstein, 2001; Muñoz, 2004; Murray y Overton, 2014). Unos enclaves turísticos, que parcialmente, se forjaron a tesón de los operadores turísticos y de los guías de viaje, quiénes tuvieron un papel clave tanto en atraer a los turistas como en transmitir un sentimiento de unidad social (Cocks, 2001). Estos empresarios proporcionaban a los visitantes itinerarios fijos, reduciendo las ciudades a un conjunto de monumentos, sitios históricos y centros culturales. La experiencia turística en el transporte masivo y los recorridos guiados redujeron la ciudad a un tour panorámico, contemplativo, pasivo, visto desde la distancia y de una manera fascinante, bello y exultante (Cocks, 2001; Harvey 2001). Las ferias, exposiciones mundiales y exhibiciones consolidaron este hábito de ver las ciudades como un collage de imágenes urbanas estilizadas, parques urbanos monumentales y escenas públicas preestablecidas (Judd, 2003; Murray y Overton, 2014). Estos procesos de turistificación se iniciaron con las transformaciones urbanas tras sus crisis industriales, en pos del embellecimiento, la rehabilitación de los espacios y la regeneración física (Blázquez y Murray, 2010; Harvey, 2012 Crespi-Vallbona y Domínguez-Pérez, 2016; Sorando y Ardura, 2016; Gil y Sequera, 2018). Unos espacios centrales turistificados, tematizados, a menudo congestionados o masificados, sin demasiada alma o autenticidad (Donaire, 2008; Herzer, 2008; Rosas Mantecón 2013; Martín, Martínez y Fernández, 2018). En cualquier caso, esta creación de imagen y marca de las ciudades fue un reto y un hábito generalizado en las urbes europeas en busca de un posicionamiento turístico en el ránquing de los destinos a visitar. Este desarrollo turístico, rápido y vivaz, no sopesó los costos del turismo, en aras a la gentrificación o las fricciones culturales de los residentes (Judd, 2003; Paskaleva-Shapira, 2007; Gladstone y Préau, 2008; Ashworth y Page, 2011; Wise, 2016; Postma y Schmuecker, 2017). Tampoco el desenlace turismofóbico o la configuración de movimientos sociales de resistencia ante la presión turística (Novy, 2017; Milano, 2017; Quaglieri y Scarnato, 2017; Huete y Mantecón, 2018; Crespi-Vallbona y Mascarilla-Miró, 2018).

En este contexto, el reto candente de los responsables de la planificación urbana y turística de las ciudades es hacer especial hincapié en el desarrollo sostenible y hacer del enclave un lugar atractivo tanto para los residentes locales como para los visitantes, apostando por la calidad de vida de los vecinos, la satisfactoria experiencia del visitante, 
la sostenibilidad del destino, la conciliación de intereses, la compatibilización de usos y usuarios (Lloyd, 2000; Crespi-Vallbona, et al., 2019). Unos espacios en los que conviven ciudadanos globales con rentas que les disponen a disfrutar de su tiempo de ocio, entretenimiento y cultura (Sassen 1994; Lury, 1997), así como turistas globales que deambulan por los espacios urbanos para vivir experiencias y emociones totalmente como residentes locales (Hoffman, 2000). Estos denominados post-turistas (Feifer, 1985) demandan interacción social, cultura, diversidad y autenticidad. Además, tienden a rechazar las "experiencias enlatadas" o de atmósfera artificial (Graham y Marvin, 2001; Judd, 2003).

Así pues, las ciudades que desean atraer visitantes invierten necesariamente en instalaciones públicas como parques, fuentes, jardines y arte público (Iyer, 2000; Graham y Marvin, 2001; Judd, 2003), enclaves que ofrecen tanto a visitantes como residentes locales por igual numerosas oportunidades para deambular, apostando e innovando para crear diversidad y diferencia, singularidad e innovación, más que monotonía y uniformidad. Unos espacios urbanos que protagonizan interacción social, sentido de pertinencia, memoria colectiva y de identidad compartida (Goodsell, 2003).

En este escenario emerge el arte urbano o street art. Este se refiere a las manifestaciones artísticas que transforman la escena pública (paredes, estaciones de metro, postes, bancos, señalizaciones viales, etc.), aludiendo a intervenciones inventivas, que conservan un estatus de "sin permiso" (Abarca, 2010) y en escenarios anonimizados de la ciudad, los denominados no-lugares de Augé (1995), o al límite de la pobreza (Gottdiener, 2000), provocando una reacción ante su discurso artístico y reivindicativo (Kelly, 1998). Generan otra esfera de consumo que los académicos han analizado desde la perspectiva de diseño de marca, cocreación, interconexión público-privada, espacio activo de interacción social. De las múltiples formas y técnicas de marcar el lugar (Borghini et al.2010)-tags, sticking, stencil, poetic assalt, etc.- el urban design que mayoritariamente supone una acción estética en pro del embellecimiento del espacio público, es el que se manifiesta en este estudio.

\section{BARCELONA: PINACOTECA A CEL OBERT. UN CASO DE ESTUDIO}

Barcelona es un destino consolidado y turistificado. Especialmente su centro histórico. El análisis de la gestión y gobernanza de la actividad turística en Barcelona es de actual debate, tanto académico como social. Por ello, este artículo reflexiona sobre una nueva forma de intervención del espacio urbano: manifestaciones artísticas en el mobiliario urbano, el denominado street art. Su finalidad no es transgredir o territorializar, sino embellecer, dialogar, decorar, visibilizar un eje comercial de la ciudad, aportando una nueva experiencia de consumo turístico y de coparticipación público-privada en su diseño y creación. El caso de estudio es el proyecto e itinerario de Pinacoteca a Cel Obert.

\subsection{Metodologia}

La observación participante, las entrevistas a los informantes clave y una encuesta a los visitantes de Pinacoteca a Cel Obert constituyen la base metodológica de esta investigación. Así como el análisis de fuentes secundarias como planes estratégicos y estudios 
llevados a cabo por el Ayuntamiento, tanto a nivel turístico, como comercial, que permiten contextualitzar el proyecto.

El trabajo de campo para esta investigación se realizó desde la primavera de 2018 hasta invierno de 2019 en Barcelona, en los distritos de Sants-Montjuïc y Les Corts. En concreto, entrevistas semiestructuradas realizadas al concejal de Educación y Cultura SantsBadal (Joan Sanromà), el 10 de diciembre de 2018; la técnica responsable de Comercio, Turismo y Promoción Económica del Distrito de Sants-Montjuïc (Neus Tormo), el 16 de diciembre de 2018; la responsable de comunicación y la vicepresidenta de la Asociación de Comerciantes de Sants-Les Corts (Ester Estany y Reyes de la Corte, respectivamente), 30 de enero de 2019; la guia-intérprete y cofundadora de Revivint el Patrimoni (Cristina Bortolotti), el 5 de febrero de 2019; el responsable de Rebobinart (Marc Garcia), el 4 de febrero de 2019. Las personas entrevistadas se escogieron a raíz de su vinculación privilegiada en el proyecto de Pinacoteca a Cel Obert. El rasgo que las une es el de dinamizar económica, social y culturalmente el barrio, así como por su participación activa en el contenido cultural y de construcción del paisaje artístico.

La encuesta a los visitantes que realizaron el itinerario se realizó al finalizar éste y mientras disfrutaban de un aperitivo-degustación (el tradicional vermouth que sobre las 12 del mediodía es tradición). En total, se recogieron 150 respuestas válidas. Ofrecen amplia información sobre los elementos clave de las experiencias vividas a lo largo del recorrido y el grado de satisfacción. Desde que la cooperativa de guías empezó su actividad en marzo de 2018, llevan realizadas 14 rutas con un total de 171 participantes. Estas rutas solo tienen lugar los domingos por las mañanas puesto que el resto de días los comerciantes tienen el establecimiento abierto y la pintura representada en la persiana no puede verse ni admirarse.

La muestra estuvo ligeramente dominada por visitantes femeninos $(53 \%)$, con estudios de grado y licenciatura $(51,9 \%)$, incluidos estudios superiores (masters y posgrados, $29 \%$ ). La mayoría presentan una franja de edad entre 35-64 años (60\%) y más del $80 \%$ de los entrevistados tienen empleo. Respecto al país de residencia de los entrevistados, el $87 \%$ de ellos procede de Barcelona (Tabla 1).

\section{Tabla 1
CARACTERÍSTICAS DEMOGRÁFICAS DE LA MUESTRA $(\mathrm{N}=150)$}

\begin{tabular}{|c|c|c|c|}
\hline & Número de encuestados (\%) & & Número de encuestados (\%) \\
\hline \multirow[t]{2}{*}{ Género } & Femenino $79(53 \%)$ & Nacionalidad & Barcelona $131(87 \%)$ \\
\hline & Masculino $71(46 \%)$ & & Otros $19(13 \%)$ \\
\hline \multirow[t]{3}{*}{ Educación } & Estudios básicos $37(24,7 \%)$ & Profesión & Empleado $121(80.47 \%)$ \\
\hline & Universidad $78(51,9 \%)$ & & Desempleado $19(12.38 \%)$ \\
\hline & Masters y posgrados $32(23,3 \%)$ & & Jubilado $10(7.1 \%)$ \\
\hline \multirow[t]{3}{*}{ Edad } & \multicolumn{3}{|l|}{ 18-34 años $24(16 \%)$} \\
\hline & \multicolumn{3}{|l|}{ 35-64 años $90(60 \%)$} \\
\hline & \multicolumn{3}{|l|}{$>65$ años $13(24 \%)$} \\
\hline
\end{tabular}

Fuente: Elaboración propia. 


\subsection{Barcelona: destino urbano consolidado}

Según Euromonitor International (2019), Barcelona se ha erigido como una de las ciudades más visitadas de Europa, situándose en la séptima posición del ránquing (véase la Figura 1). Un breve análisis histórico indica que el primer plan turístico desarrollado por el Ayuntamiento de Barcelona (1988-1992) tuvo el claro objetivo de posicionar la ciudad en la escena turística mundial y de proporcionar la capacidad de alojamiento suficiente para acomodar a los participantes y observadores de los Juegos Olímpicos de 1992. Así, los Juegos Olímpicos pusieron a Barcelona en el mapa, en la mente del potencial turista extranjero, creando una imagen y una marca vinculadas a la idea de cosmopolitismo, modernidad, diseño y tradición, con un carácter abierto y acogedor de sus residentes (Alabart Vilà et al., 2015), destacando el Barrio Gótico y la obra del conocido artista modernista Gaudí (Palou, 2019).

Figura 1

CIUDADES EUROPEAS MÁS VISITADAS (2016-2019)

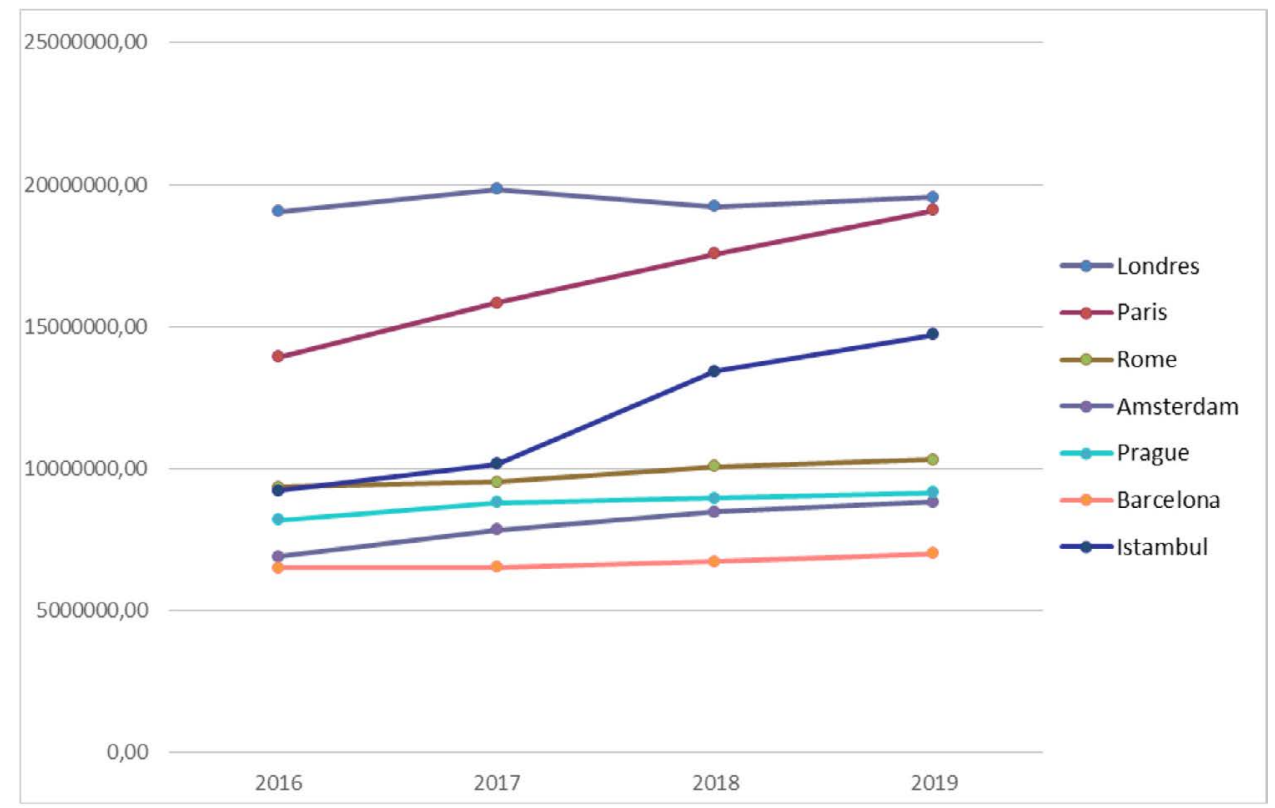

Fuente: Elaboración propia a partir del Euromonitor International Report, 2019.

Los iconos culturales atractivos de Barcelona se encuentran principalmente en el centro histórico. La Rambla, la Catedral, el Barrio Gótico... son los lugares más visitados. La saturación y congestión de estos espacios centrales ha conllevado el surgimiento de distintos movimientos sociales de resistencia a la actividad turística (Mansilla, 2018). También ha suscitado la reacción de la administración local con la aprobación de distintos planes estratégicos y medidas de usos, límites y licencias de los espacios turistificados. 


\subsection{Los Planes Estratégicos}

Las organizaciones que gestionan los destinos turísticos (Destination Management Organizations, DMO) son usualmente entes públicos que se ocupan de la competitividad de un destino, de su marca (Presenza et al., 2005). Kavaratzis (2004) considera que la marca de un destino tiene un doble efecto. Por un lado, sirve para lograr ventaja competitiva con el fin de incrementar la inversión local y el turismo. Del otro, permite el desarrollo de la comunidad, reforzando la identidad local y la identificación de los ciudadanos con su ciudad. Para ser capaces de implementar esta competitividad y marca son necesarios dos aspectos, liderazgo estratégico y creación y gestión de redes (Volgger y Pechlaner, 2014). Para ello se precisa formular estrategias, representar a los intereses de todos los stakeholders, desarrollar productos y tener un plan de desarrollo y gestión sostenibles (Velasco-González, 2013). En este sentido, Landry (2012) emfatiza en la necesidad de la creatividad como un nuevo método de planificación estratégica y de éxito turístico. Jamal y Camargo (2018) añaden la necesidad de establecer procesos colaborativos y participativos para desarrollar tales estrategias diseñadas.

Barcelona es una ciudad donde el turismo está totalmente insertado en su dinámica económica, comercial, social y cultural, y en la que se perciben constantes transformaciones en el tejido urbano, su movilidad, las actividades económicas y también en la vida cotidiana de muchos barrios. Esta apuesta por proyectarse internacionalmente como una ciudad moderna y atractiva ya se contempla en la Exposición Universal de 1888 y la Exposición Internacional de 1929. Una necesidad de crear imagen que se acompaña de la recuperación del medievalismo y del Gótico en el sí de la ciudad histórica, configurando una identidad formal y simbólica basadaos en este pasado. Todo ello, divulgado por la Sociedad de Atracción de Forasteros, una iniciativa pública y finanzada con fondos privados para difundir unos determinados valores culturales, naturales, industriales y comerciales de la ciudad (Palou, 2019). Sin embargo, cuando el turismo se convierte en uno de los sectores prioritarios de la economía es a tenor de los Juegos Olímpicos, cuando se consigue consolidar la ciudad internacionalmente. Aprovechando esta dinámica se crea el Consorci Turisme de Barcelona en 1993, entre el Ajuntament de Barcelona y la Cambra de Comerç de Barcelona, con el objetivo de trabajar para mantener el auge turístico de la ciudad. Sin considerar los mandatos políticos de los diferentes gobiernos, la administración local de Barcelona ha considerado el turismo como una actividad estratégica. Por ello, en 2008, siguiendo las orientaciones del Plan de Actuación Municipal (PAM) 2008-2011, prepara el Plan Estratégico de turismo de Barcelona 2015. El objectivo básico de este plan consiste en desarrollar un modelo turístico, basado en la participación y la conciliación, capaz de asegurar la sostenibilidad económica, social y medioambiental de la ciudad. Ciertamente se abren procesos de reflexión abiertos y participativos, que desencadenan en el Plan Especial Urbanístico de Alojamientos Turísticos (PEUAT, 2017 -que por el momento no ha podido implementarse-) y en el actual Plan Estratégico de Turismo 2020 (PET20). Su reto es no solo gestionar el turismo en la ciudad, sino cómo gestionar la ciudad con el turismo, es decir, cómo garantizar la convivencia de la ciudad turística con el resto de las necesidades de la ciudad. En definitiva, el objetivo claro es gestionar los impactos y las externalidades del turismo, así como la necesidad de innovar en formas de coordinación y coproducción entre los agentes. 
Estos objetivos del PET20 se delegan en los técnicos de los Distritos. Territorialmente, desde 1984, Barcelona se conforma en 10 distritos (Mapa 1), mayoritariamente fruto de la unión de diferentes municipios. En 2009, con el objetivo de acercar sus políticas al ciudadano, estos distritos se subdividen en 73 barrios.

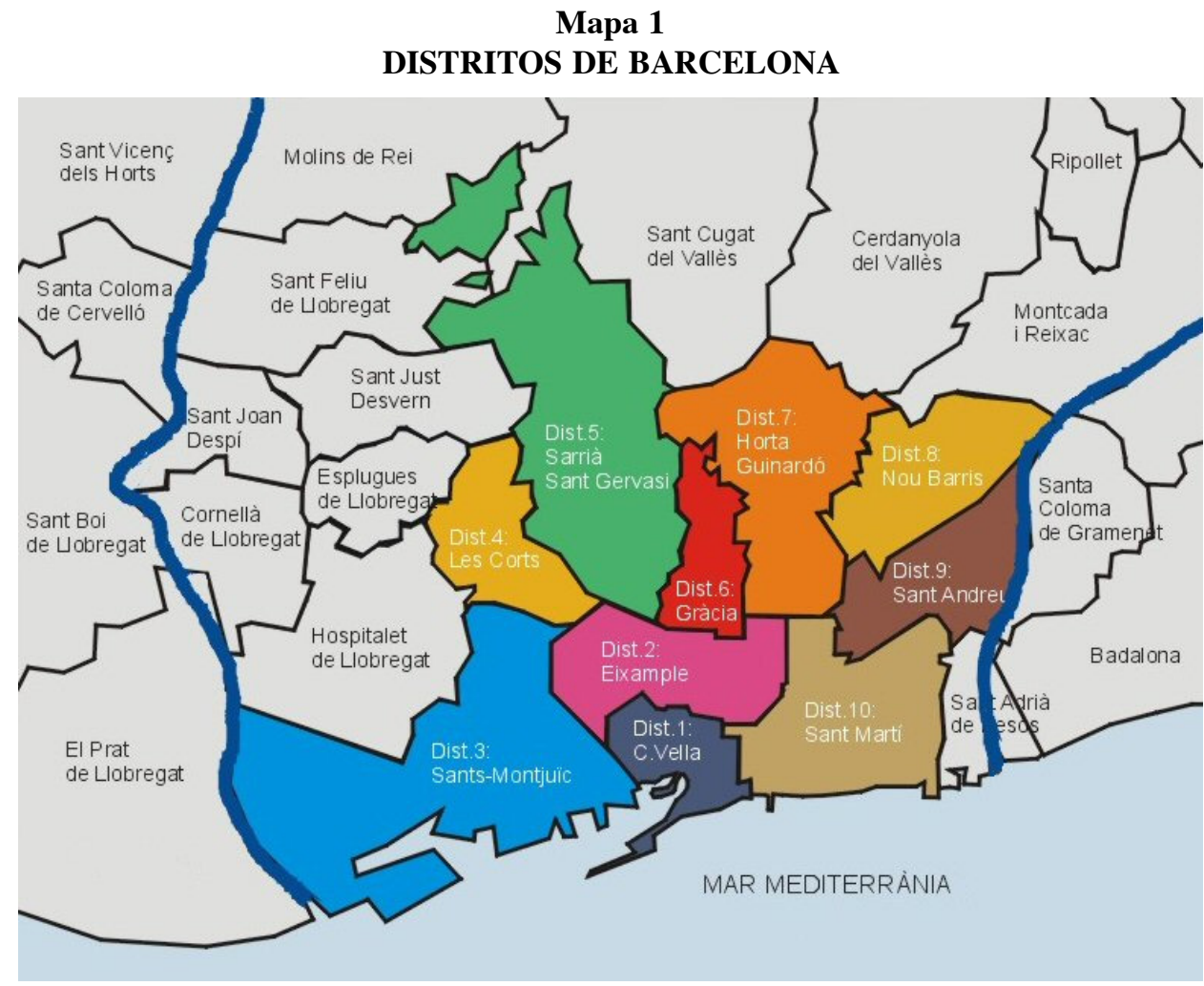

Fuente: Ayuntamiento de Barcelona.

En consecuencia, desde la Administración de los Distritos, concretamente desde el área de Comercio, Turismo y Promoción Económica se impulsan diferentes líneas de actuación, según las prioridades marcadas en el plan estratégico vigente, el PET20, en el que se destacan: a) la conservación del patrimonio cultural y de los espacios naturales; b) la voluntad de dar a conocer el territorio; c) garantizar la actividad económica del tejido local; d) emprender proyectos colectivos que velen por la ciudad en su complejidad como espacio común; e) fortalecer los vínculos de las actividades turísticas con los agentes y la población del territorio.

\subsection{Acciones innovadoras y redes}

Con la voluntad de conseguir llevar a cabo estos objetivos, se constata la necesidad de la creatividad e innovación. El diseño y creación de productos turísticos es funda- 
mental para la gestión de los destinos y la satisfacción de los visitantes. Por tanto, los responsables de los destinos tienen la necesidad de conocer y analizar las tendencias de los consumidores en su tiempo de ocio y descubrir qué componentes, qué atributos deben conforman aquellas experiencias o vivencias en las que participan. En la actividad turística, los visitantes compran una ilusión, tienen una expectativa, buscan satisfacer unas necesidades (Crompton y McKay, 1997). Actualmente, para cumplir con estas expectativas y satisfacer estas necesidades, deben crearse actividades basadas en la experiencia, en las emociones (Vogeler y Hernández, 2002; Bordas, 2003; Bonilla Moya, 2006; de Rojas y Camarero, 2008; Cuenca y Prat, 2012; Rivera Mateos, 2013). Los cambios en la demanda turística suponen una búsqueda de experiencias que les evadan de su rutina, que les permitan descubrir y conocer otras culturas, otros espacios de ocio, disfrutar y conectar con la gente del lugar y con sus costumbres; vivir historias para contar, sentir emociones y recordar momentos de su pasado (Crespi-Vallbona, 2021). Ya constataban Pine y Gilmore (1998) que las actividades basadas en la experiencia debían articularse a través de los cuatro ámbitos de la realización de la experiencia: entretenimiento, educación, estética y escapismo, sin olvidar el papel central que juegan los sentimientos (Holbrook y Hirschman, 1982). En definitiva, tales experiencias deben conformarse con unos atributos básicos, tales como: participación, hedonismo, identidad local, conocimiento, degustación y nostalgia (Figura 2). Estos atributos configuran una experiencia global en la que las diferentes necesidades y motivaciones de los visitantes se cubren y completan de manera holística (Crespi-Vallbona, 2021).

\section{Figura 2}

\section{COMPONENTES DE LAS EXPERIENCIAS HOLÍSTICAS}

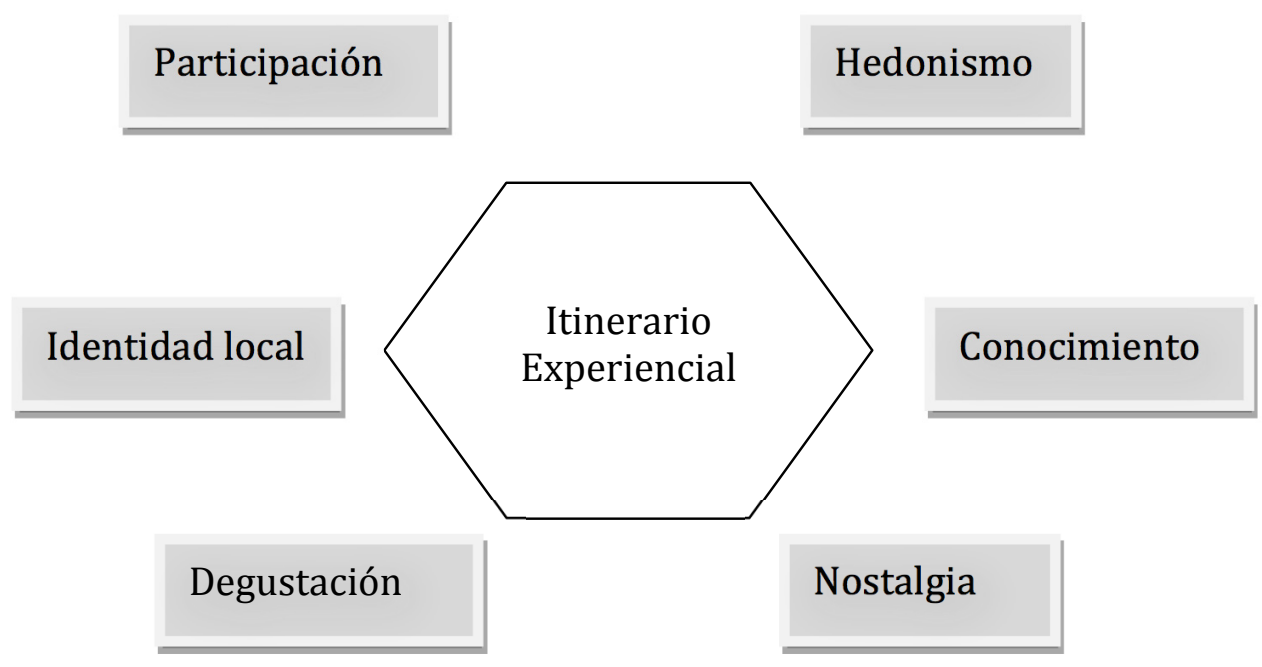

Fuente: Elaboración própia (adaptado de Crespi-Vallbona, 2021). 
Que un itinerario o ruta sea memorable significa que al menos una parte de la cadena de valor tiene un mérito añadido, un cúmulo de sentimientos que sugieren, evocan, transmiten y recuerdan (Crespi-Vallbona, et el, 2017). Un recuerdo puede ceñirse a un instante puntual o a un conjunto de momentos diferentes. Pero, en esencia, la memorabilidad suele ir más allá de esa imagen o cúmulo de recuerdos plasmados, y se fusiona y combina con todo el repertorio de experiencias y emociones que son responsables de esa capacidad de dar relevancia en el tiempo. Por ello, lo memorable no es la marca, sino lo que se vive, lo que se experimenta, lo que se siente. Para medir las experiencias turísticas memorables, se incluyen las variables de satisfacción de Tsai (2016) en los itinerarios holísticos: hedonismo, participación, identidad local, conocimiento, degustación y nostalgia.

La variable hedónica supone la existencia de aspectos multisensoriales, divertidos y placenteros (Hirschman y Holbrook, 1982; Gnoth, 1997; Goossens, 2000; Aho, 2001; Barrett, et al., 2007; Frijda, 2005; Hosany, 2012; Malone et al, 2014). Mayoritariamente, se destacan los sentidos visuales, como Urry y Larsen (2011) que se centran en la "mirada". Otros se basan también en lo olfativo (Dann y Jacobsen, 2002). Pero en cualquier caso, se precisa añadir ingredientes que desencadenen ilusiones sensoriales (Pan y Ryan, 2009) positivas, de placer, de alegria.

Por otro lado, la era del turismo contemplativo ha cedido el paso a la era del turista participativo, activo, dinámico, interactivo (Herbert, 2001), lo que supone una intensidad de satisfacción mucho mayor (Troye y Supphellen, 2012; Navarro et al., 2016; Prebensen et al., 2016). Esta participación incluye la realización de acciones cognitivas como el aprendizaje y la recopilación de conocimiento, la immersión en el destino, el intercambio de información e interacción con los residentes locales (Yi y Gong, 2013; Larsen y Meged, 2013; Sharpley, 2014), incluso entre los propios visitantes, discutiendo, compartiendo, observando y destacando varios elementos concretos durante la actividad (Allen, 2003; Kidd, 2016). Por ello, las experiencias que demandan consumir los visitantes precisan de vivencias activas, de interacciones constantes, de actividades dinámicas que obliguen al visitante a tener un papel protaginsta tanto cognitivo, como ejecutivo y emotivo.

La tercera variable es la identidad local. La globalización en la que las sociedades actuales se encuentran immersas conlleva a la revalorización de la esencialidad local, a la reclamación de la particularidad local. Una identidad local que reúne un conjunto de atributos tangibles e intangibles socialmente compartidos y diferenciados de otras culturas, que un destino reconoce y utiliza como imágenes de marca para posicionarse (Crespi-Vallbona y Richards, 2007). Unas imágenes que son cada vez más codiciadas por los turistas (Stamboulis y Skayannis, 2003; Edensor, 2008), puesto que se vinculan al pasado, absorben la esencia del territorio, penetran en el carácter de sus gentes, reflejan la idiosincrasia e identidad de una comunidad. En ese sentido, esta herencia local deviene un icono para el destino y una necesidad para el visitante (Wearing, et al., 2010; Modlin et al., 2011). En una era de globalización, existe un deseo particular de disfrutar de un ambiente glocal, en lugar de atmosferas homogéneas y monoculturales.

Este atributo, conduce a la cuarta variable: la transmisión de conocimiento. Los turistas, de manera especial los culturales, se sienten atraídos por la adquisición de conocimiento, la recopilación de nueva información, la significancia de la novedad (Hughes, 1991; Kerstetter et al., 2001; Mckercher y du Cros, 2002; Tsai, 2016). De hecho, viajar 
ha sido tradicionalmente una forma generalizada de aprendizaje, como ya lo ratificaron los aristócratas ingleses que practicaron el Gran Tour (Ritchie y Crouch, 2003; Alabart et al., 2015). También hoy, la búsqueda de conocimiento, la necesidad de immersión y comprensión de algo novedoso, desconocido, que se ofrece a través del viaje, se ha convertido en una parte integral y satisfactoria de cualquier experiencia turística.

Por otra parte, diferentes académicos ya han constatado como la degustación de platos típicos, no solo complementa cualquier experiencia viajera, sino que añade valor a la immersión e integración en el destino (Boniface, 2003; Henderson, 2009; Sims, 2009; Crespi-Vallbona, et al., 2017). Diseñar actividades experienciales en las que se destaque un momento de degustación de platos locales, se saboreen gustos diferentes, conlleva una gratificación y satisfacción immediatas en el turista amante de experiencias singulares.

Por último, la nostalgia también es un aspecto significativo de experiencias satisfactorias (Hung et al., 2016; Campos et al., 2016), al desencadenar y sugerir un significativo conjunto de sentimientos de un momento específico y privado del pasado (Willson y McIntosh, 2008). Y todos estos momentos recordados, memorables, son los que refuerzan la experiencia del visitante saboreando muchas emociones reales y vividas. En la línea de Urry (2002), esta nostalgia, esta memorabilidad que postula la experiencia turística implica una variedad de paisajes sensoriales, incluidos los paisajes sonoros, los olfativos, los gustativos e inclusive, de tacto.

Las redes que se tejen en el proyecto Pinacoteca a Cel Obert incluyen el sector público, el privado y la ciudadanía (como se verá en el siguiente apartado). El enfoque de gobernanza de redes (Hall, 2011) centra su gestión en un liderazgo estratégico (van der Zee et al., 2017), tanto dentro como fuera de la red, que coordine las distintas redes, tanto públicas como privadas (Hall, 2011; Beaumont y Dredge, 2010) para la financiación, la información y la consecución de los objetivos, intereses y recursos (Vásquez Cárdenas, 2013). De todo ello se desprende la creación de un producto, con su plan de desarrollo (Velasco González, 2013).

\subsection{Pinacoteca a Cel Obert}

El caso que se presenta, Pinacoteca a Cel Obert, reúne todas estas variables mencionadas que configuran itinerarios experienciales y memorables. Y, además, representa una propuesta a replicar por su carácter innovador, participativo y de gobernanza sostenible a través de las redes creadas entre el sector público, el privado y la ciudadanía, donde la colaboración y la complicidad son la pauta de actuación.

Se define Pinacoteca a Cel Obert como una experiencia de consumo de un espacio público. Un proyecto que se delimita geográficamente en un área urbana que acomete dos distritos de Barcelona, Sants-Montjuïc y Les Corts, en concreto, en el denominado Eix Comercial de Sants-Les Corts (Mapa 2), en cuya zona de influencia se ubica l'Associació de Comerciants Sants-Les Corts, quien vela por la dinamización económica, comercial, social y cultural de su eje. 


\section{Mapa 2 \\ EJES COMERCIALES EN BARCELONA}

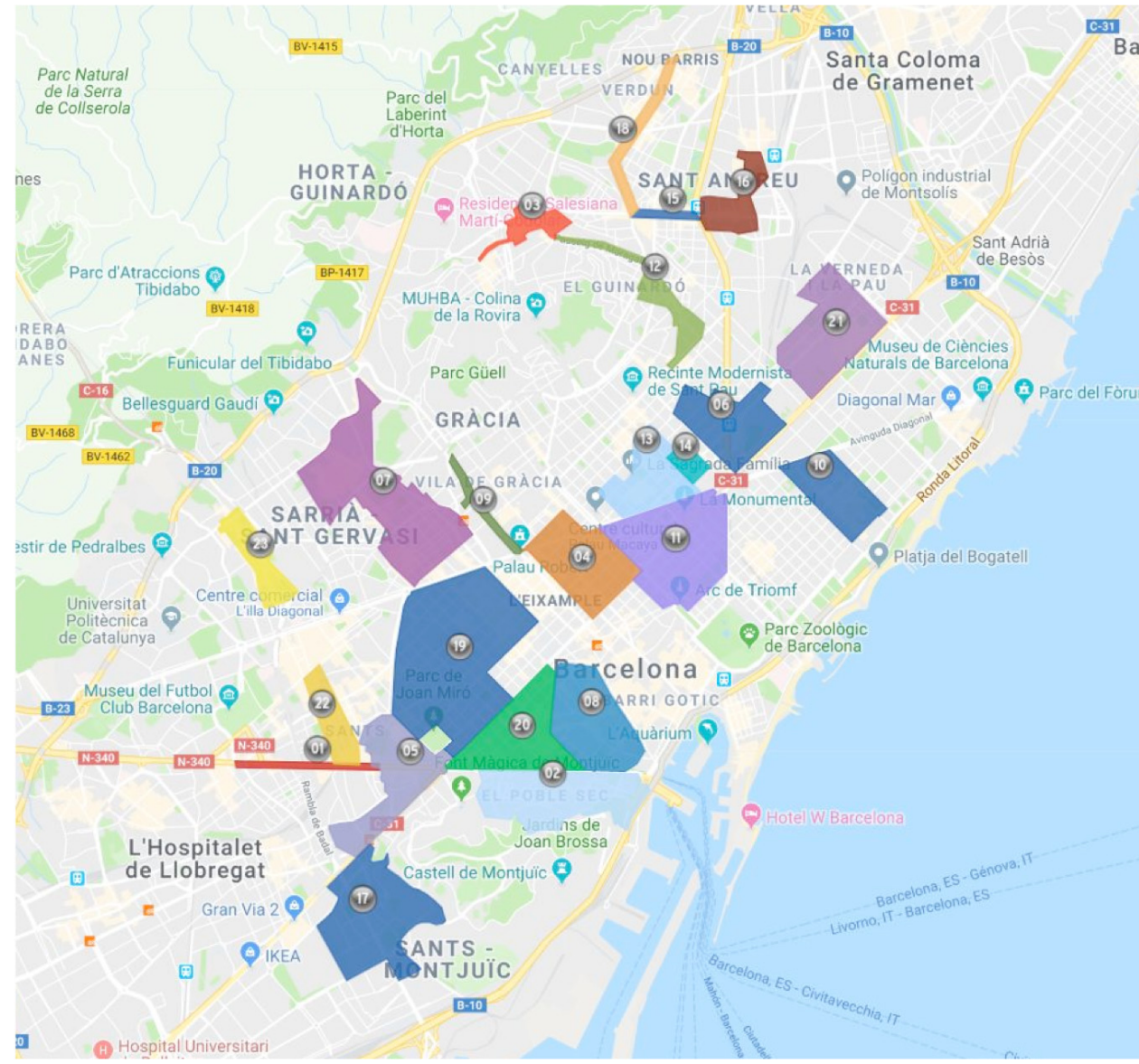

Fuente: http://www.eixosbcn.org/cat_eixos_barcelona.html

\begin{tabular}{|c|c|c|c|c|}
\hline 1. Carrer de Sants & 6. Eix Clot & $\begin{array}{l}\text { 11. Eix Fort } \\
\text { Pienc }\end{array}$ & $\begin{array}{l}\text { 16. L'Eix de } \\
\text { Sant Andreu }\end{array}$ & $\begin{array}{l}\text { 21. Sant Martí } \\
\text { Eix Comercial }\end{array}$ \\
\hline $\begin{array}{l}\text { 2. Comerciants } \\
\text { Poble Sec i } \\
\text { Paral } \cdot \text { lel }\end{array}$ & $\begin{array}{l}\text { 7. Eix Comercial Sant } \\
\text { Gervasi (Barnavasi) }\end{array}$ & 12.Eix Maragall & 17. La Marina & $\begin{array}{l}\text { 22. Sants-Les } \\
\text { Corts Eix } \\
\text { Comercial }\end{array}$ \\
\hline 3. Cor d'Horta & $\begin{array}{l}\text { 8. Eix Comercial del } \\
\text { Raval }\end{array}$ & $\begin{array}{l}\text { 13. Eix Sagrada } \\
\text { Familia }\end{array}$ & $\begin{array}{l}\text { 18. Nou Barris } \\
\text { Centre Comerç }\end{array}$ & $\begin{array}{l}\text { 23. Sarrià eix } \\
\text { Comercial }\end{array}$ \\
\hline 4. Cor Eixample & $\begin{array}{l}\text { 9. Eix Comercial Gran } \\
\text { de Gràcia }\end{array}$ & $\begin{array}{l}\text { 14. Encantsnous } \\
\text { Eix Comercial }\end{array}$ & $\begin{array}{l}\text { 19. Nou } \\
\text { Eixample }\end{array}$ & \\
\hline 5. Creu Coberta & $\begin{array}{l}\text { 10. Eix Comercial } \\
\text { Poblenou }\end{array}$ & 15. Fabra Centre & $\begin{array}{l}\text { 20. Sant } \\
\text { Antoni Comerc }\end{array}$ & \\
\hline
\end{tabular}


Se trata de una experiencia codiseñada desde la propia ciudadanía con el gobierno local (Distritos de Sants-Montjuïc y Les Corts, área de economía, promoción y turismo), implementada por una empresa cultural (Rebobinart) y ejecutada por dos artistas activos y reconocidos del arte urbano (Jalon de Aquiles y Lucie Blin). Finalmente, el proyecto se consolida con la constitución de una cooperativa de guías e intérpretes (Revivint el Patrimoni). Todos ellos asumen un papel protagonista en la proyección de estos denominados "urbanscapes" contemporáneos (Wang, 2005; Bonfantini, 2015), es decir de dinamizar culturalmente 24 puertas o persianas pintadas de diferentes negocios comerciales, en las que se han reproducido obras clásicas de pintores reconocidos en la historia del arte. Las obras y diseños se escogen junto con los dos muralistas, Jalón de Aquiles y Lucie Blin y los propietarios de los comercios, basándose en la concepción propia del negocio, primando el tipo de producto o servicio que ofrecían. Por tanto, el artista no expresa sus sentimientos, sino que reproduce una obra clásica.

L'Eix Sants-Les Corts es el área comercial elegida de este estudio y de este proyecto: Pinacoteca a Cel Obert. Según los datos del Informe Eixos del Comercio en Barcelona (2018), Sants-Les Corts Eix Comercial cuenta con más de 500 comercios activos, de entre los que el $22 \%$ se dedica a ofrecer bienes de compra comparada (equipamientos para la persona, equipamientos para el hogar, cultura y ocio). Los servicios comerciales, así como la hoteleria y la restauración, representan más del 50\% de la actividad comercial del eje. El comercio alimenticio cotidiano representa el 11,6\%. En este Eje se constituye en 2006, la Associació de Comerciants Eix Sants-Les Corts con el objetivo de dinamizar comercial, y también social y culturalmente su eje, teniendo en cuenta que los hábitos de compra han cambiado, y que en consecuencia también la composición de los comercios locales. La preocupación del Eje por recuperar su atractividad comercial les conduce a trabajar con el Distrito y a elaborar un proyecto innovador y revulsivo de dinamización y revitalización del área económica territorial. Este proyecto es Pinacoteca a Cel Obert: la elección de 24 comercios, en el exterior de cuyo establecimiento se pintará una obra de arte. Su interés es evitar que las persianas de los comercios se degraden con pintadas arbitrarias de muralistas siguiendo la estética propia del street art. Rebobinart es la asociación cultural que colabora en el diseño e implementación del proyecto.

Rebobinart es una organización cuya misión es cambiar la forma de entender el arte urbano en la ciudad de Barcelona. Gestiona espacios de creación y experimentación cultural en las calles de la ciudad, en la que el arte es de acceso libre, con el objetivo de suscitar el encuentro y la reflexión con el peatón casual. Conscientes de la problemática social que comportan las firmas o tags más invasivos, Rebobinart potencia aquellos artistas que apuestan por la calidad y son capaces de mantener un discurso crítico del arte urbano dentro de los espacios públicos legales y consensuados con los vecinos de los barrios. Concretamente, con el proyecto Pinacoteca a Cel Obert, Rebobinart se fija varios objetivos: i) promocionar la red de comercios a través de la cultura, estableciendo un recorrido físico, histórico y artístico a través del eje comercial (Sants-Les Corts). ii) Favorecer la atracción de visitantes que gozan de su tiempo de ocio y son amantes del arte urbano. iii) Fomentar la cohesión vecinal y de comerciantes de Les Corts y de Sants. iv) Por último, evitar que las persianas que protegen y cierran los establecimientos sean pintadas con tags invasivos. Consecuentemente, como constata el responsable de la organización, la princi- 
pal labor de Rebobinart fue la de convencer a los muralistas que pintaran obras clásicas, puesto que su obra mural es libre y no sigue los cánones de réplica de obras clásicas de la historia del arte.

Paralelamente (inicios de 2017), la administración planifica y desarrolla un curso de formación en guiaje e interpretación de patrimonio, tanto natural como cultural para personas desempleadas temporales o de larga duración. El curso consta de un apartado de formación técnica de como conducir grupos y diseñar itinerarios experienciales con una propuesta clave: generar memorabilidad. Por ello, se incluyen las variables de hedonismo, participación, identidad local, conocimiento, degustación y nostalgia. Consecuentemente, son los guías-emprendedores del curso ocupacional llevado a cabo por la administración del Distrito, quiénes empiezan a diseñar un itinerario experiencial por los establecimientos del eje con pinturas urbanas. Un diseño de itinerario que atiende a los diferentes elementos que componen la satisfacción de estas visitas culturales. La continuidad de las rutas se debe a la cooperativa creada por estos emprendedores para desempeñar propiamente estas actividades de guiaje. Se trata de Revivint el Patrimoni.

\subsection{Análisis de los discursos}

Las entrevistas, la participación observante y la encuesta nos dan información del carácter sostenible del proyecto y de la importancia de cada uno de los atributos que conforman el diseño del itinerario experiencial.

La sostenibilidad y éxito del proyecto están garantizados dado el consenso, compromiso y complicidad generados en su diseño, elaboración y ejecución con la administración local, los empresarios de los comercios y los ciudadanos-guías. Esta triple alianza, esta corresponsabilidad se percibe durante las visitas, cuando los propietarios, si aquella mañana tienen abierto el local, presentan con extrema felicidad y entusiasmo el proyecto llevado a cabo y el resultado final.

En cuanto a los componentes de las visitas, la Figura 3 muestra en qué proporción los visitantes han valorado la importancia de cada atributo en la percepción de su visita, como una experiencia memorable, participativa, emotiva, con significancia cognitiva.

La participación, con un $96 \%$, es uno de los atributos que destacan más positivamente de la experiencia. Concretamente, y como ejemplo a destacar de momento más álgido, es cuando el guia solicita a los visitantes que se tapen los ojos para poder observar la obra del comercio Fap (especialitzado en la restauración de coches de época y todo tipo de vehículos) que evoca "Muerte en el camino de la cima", de Grant Wood, y en la que el guía pregunta qué ven o qué destacan del mural, no sin antes haber construído unas lentes-antifaz para focalizar la mirada en el punto exacto, es decir, el camión rojo (Fotografía 1). También es muy dinámica la actividad delante de la obra de Renoir, "La lectura" del negocio de Kids \& Us para el aprendizaje del inglés, en el que se invita a hablar y recomendar el libro que se está leyendo. Estas interacciones e intercambio de información es lo que destacan los encuestados. También valoran reiteradamente la conversación que mantienen con los propietarios de los negocios. 


\section{Figura 3 \\ PERCEPCIÓN DE SATISFACCIÓN DE LA EXPERIENCIA TURÍSTICA SEGÚN SUS ATRIBUTOS (\%)}

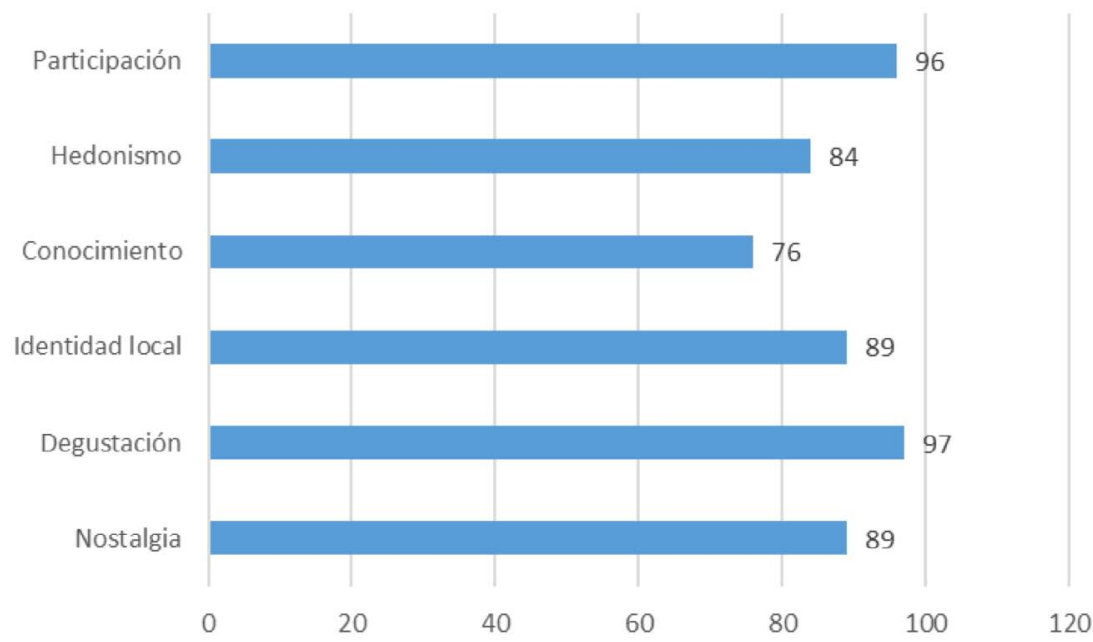

Fuente: Elaboración propia.

Fotografía 1

VISUALIZANDO "MUERTE EN EL CAMINO DE LA CIMA" DE GRANT WOOD

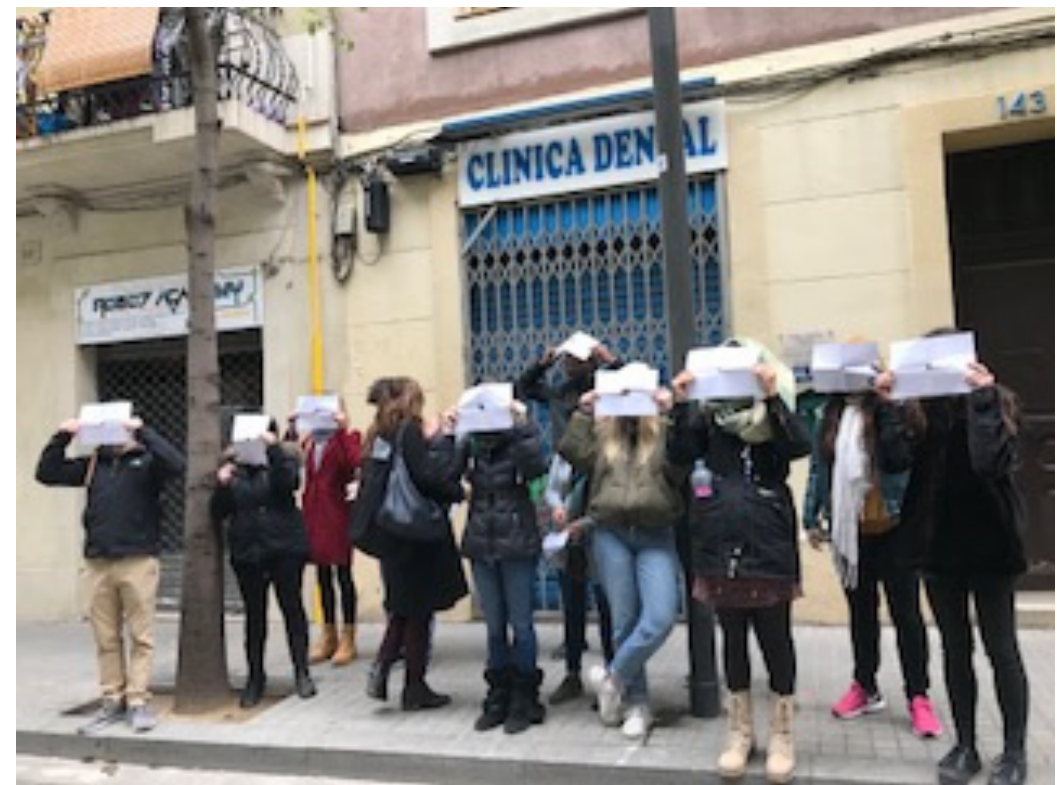

Fuente: Elaboración propia. 
En lo que se refiere al hedonismo, estas experiencias son placenteras, los domingos por la mañana, con un ritmo pausado, disfrutando de cada uno de los murales. Los visitantes concluyen que este atributo tienen una relevancia de $84 \%$, independientemente que el día sea menos soleado. Lo único que manifiestan con aire molesto, es la estrechez de las aceras, los coches aparcados y el constante tráfico, lo que impide poder admirar con más calma y atención cada persiana pintada. Es en este sentido que las áreas de promoción económica urbanas (APEU) cobran importancia en los debates, es decir, las zonas amplias, peatonales, de promoción e interés comercial.

En cuanto a la variable del conocimiento, situar en el tiempo cada obra, cada artista, cada época estilística, representa un interés y valor añadido para cada participante. Para ellos es percibido como un concurso, una competición de conocimiento. Finalizan la visita con una sensación de aprendizaje, de haber recordado aquello aprendido en sus años de escolarización obligatoria, de haber mejorado sus conocimientos históricos y artísticos, de haber sido sorprendidos, como es el caso del mural que recuerda a van Gogh con "El comedor de patatas", una obra bastante desconocida de este celebre autor que no obstante representa muy bien el negocio de la Metalisteria Sánchez (material de construcción, lamparas e iluminación). Sin embargo, este componente es el que menos priorizan los encuestados $(76 \%)$, aunque ello no signifique que no lo consideren relevante para la satisfacción de su experiencia.

La referencia a la identidad local es otro aspecto clave del itinerario puesto que en cada parada se hace especial énfasis en el negocio de cada comercio y en porqué su propietario escogió aquel determinado artista y aquella obra concreta. Por tanto, se explican las particularidades del negocio, y si, en alguna ocasión, el propietario està trabajando en el local y tiene el negocio abierto, éste acostumbra a ser invitado a participar de las explicacions y a añadir más detalles personales. Esto es lo que significativamente más agradecen los usuarios, en un $89 \%$, como en el caso de la tienda La Peculiar (que vende productos culinarios selectos) con un bodegón de Goya, o el negocio Jamón Jamón (charcutería, quesería y producto gourmet) con una intervención mural que nos acerca a Sorolla con "Mercado de cerdos" o la Joyeria Europa con la obra de Alfons Mucha, "Rubí", que diseña y crea joyas (a demanda) de la misma época y estilo de la obra: el modernismo.

Es en el momento de la degustación, ya en la etapa final del itinerario, cuando delante de un negocio de fruta ecológica y de temporada, Capità Enciam, con un mural precisamente titulado "Fruta" de Mucha, que el guia invita a sus visitantes a degustar y saborear fruta de temporada, de proximidad y de calidad. Este es un momento que también invita a la interacción, a comentar los gustos y sabores que a cadauno más le entusiasman, es un momento de acercamiento, de cohesión entre el grupo. El 97\% de los encuestados comentaron que este atributo en la experiencia fue uno de las mejores y más sorprendentes. Es el momento de promoción del eje, del comercio de proximidad, del comercio de barrio.

El último componente de la experiencia tiene que ver con la nostalgia. Cuando el visitante experimenta y vive un momento especialmente emotivo, nostálgico es ante la persiana del negocio Goccia Verde (dedicado a detergentes y productos de higiene a granel y ecológicos) que con la obra de Claude Joseph Bail "Burbujas" (Fotografia 2), los participantes recuerdan los juegos de su niñez, los momentos de juego en sus casas, patios, terrazas, amigos.... Se trata de un momento mágico del itinerario, de gran comunicación entre todos los 
participantes, normalmente jugando a las burbujas de agua y jabón y contando con emoción su niñez y su juego favorito, tal y como lo manifiesta en un $89 \%$ los encuestados.

\section{Fotografía 2}

VISUALIZANDO “BURBUJAS” DE CLAUDE JOSEPH BAIL

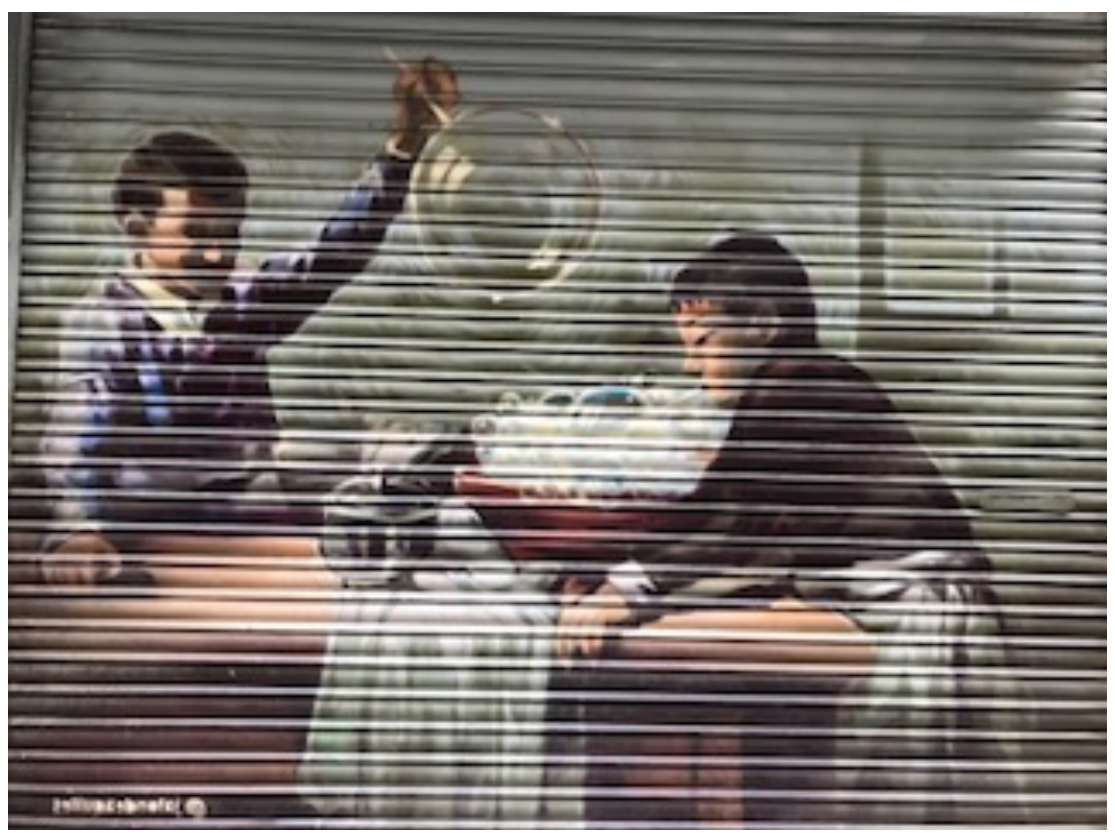

Fuente: Elaboración propia

A modo de conclusión, los visitantes lamentan que esta ruta solo sea factible los domingos por la mañana, y que no exista una app para recorrer libremente las calles e ir aprendiendo al detalle lo que se sucede en ese comercio con su obra icónica. También demandan mapas para que puedan ubicarse y folletos explicativos y/o promocionales, puesto que apenas se encuentran en las sedes de los respectivos distritos. Tanto menos en las oficinas de promoción turística de la ciudad de Barcelona. Por último, constatan una falta de señalización de la ubicación de este street art, de esta galeria abierta.

\section{CONCLUSIONES}

En este estudio se ha enfatizado en un modelo de gobernanza basado en la coparticipación y corresponsabilidad entre los diferentes stakeholders implicados y afectados por la actividad turística: administración pública, sector privado y ciudadanos. Un modelo que apuesta por la sostenibilidad y la cohesión entre los diseñadores y ejecutores de los proyectos turísticos; que busca fortalecer los vínculos de las actividades turísticas con los agentes y la población del territorio; y que impulsa nuevas formas de gestión y organización que generan valor compartido para el beneficio mutuo. 
También se han analizado los elementos que constituyen experiencias holísticas, visitas vivenciales. En el caso concreto de Pinacoteca a Cel Obert, ha quedado demostrado como los participantes en el itinerario disfrutaban del arte urbano, recordando momentos del pasado, comentando con los demás una situación emotiva, como se creaba un ambiente idóneo para compartir aspectos personales, como se generaba una atmósfera apta para participar, interactuar, aprender, para insertarse en el contexto visitado, el eje comercial de Sants-Montjuïc y sus peculiaridades locales. Esta experiencia, este viaje emocional, esta visita altamente satisfactoria se consigue cuando los productos turísticos se diseñan tomando en cuenta unos determinados componentes: velando por una participación activa y hedonista, con adquisición de nuevos conocimientos, con la evocación de recuerdos nostálgicos, sin que falten los momentos de degustación e identidad local.

Por otro lado, el artículo también remarca un nuevo concepto de street art, como excusa para revalorizar una comunidad, revitalizar una zona comercial, apoyar el emprendedor local, embellecer un espacio público. Seguramente, a pesar del embellecimiento del espacio público con las reproducciones de distintas obras clásicas, sería necesario repensarlo urbanísticamente en pro de las áreas de promoción económicas urbanas (APEU). Estas áreas garantizan espacios donde las actuaciones en pro del comercio son apoyadas y soportadas impositivamente por todos los negocios, evitando los recelos que se derivan de las actuales asociaciones de comerciantes, de carácter meramente voluntario y corporativista. En este proyecto, solo los comercios de la Asociación de Comerciantes Eix Sants-Les Corts se embellecen mediante el street art, siguiendo una estética unificada, coherente, singular y de calidad.

Declaración responsable: Los autores declaran que no existe ningún conflicto de interés en relación a la publicación de este artículo. Las tareas se han distribuido del modo siguiente. El diseño general del artículo ha sido obra de Montserrat Crespi Vallbona, así como el apartado de Discusión de los resultados y las fuentes de información históricas y administrativas. La aplicación metodológica, redacción del texto y revisión bibliográfica ha sido responsabilidad de ambos autores.

\section{REFERENCIAS}

ABARCA, J. (2010): "El papel de los medios en el desarrollo del arte urbano", Revista de la Asociación Aragonesa de Críticos de Arte, $\mathrm{n}^{\circ}$ 12, pp. 1-6.

AHO, S.K. (2001): "Towards a general theory of tourist experiences: Modelling experience process in tourism", Tourism Review, vol. 56 (3), pp.33-37.

ALABART VILÀ, A., DOMÍNGUEZ-PÉREZ, M. y CRESPI-VALLBONA, M. (2015): "Turismo y ciudad", en Procesos de transformación urbana y social. Similitudes y disimilaridades. Madrid, Síntesis, pp. 247-274.

ALLEN, S. (2003): "Looking for Learning in Visitor Talk: A Methodological Exploration", en Learning conversations in museums. Mahwat, New Jersey, Lawrence Erlbaum Associates, pp. 259-303.

ASHWORTH, G. y PAGE, S. J. (2011): “Urban tourism research: Recent progress and current paradoxes", Tourism Management, vol. 32 (1), pp. 1-15. 
AUGÉ, M. (1995): Non-places: Introduction to an Anthropology of Supermodernity. New York, Verso.

BARRETT, L.F., MESQUITA, B., OCHSNER, K.N. y GROSS, J.J. (2007): “The experience of emotion", Annual Review of Psychology, vol. 58, pp. 373-403.

BEAUMONT, N. y DREDGE, D. (2010): "Local tourism governance: A comparison of three network approaches", Journal of Sustainable Tourism, vol. 18, pp. 7-28.

BLÁZQUEZ SALOM, M. y MURRAY MAS, I. (2010): "Una geohistoria de la turistización de las islas Baleares”, El Periplo Sustentable, n 18, pp. 69-118.

BONFANTINI, G. B. (2015): "Historic Urbanscapes For Tomorrow, Two Italian Cases: Genoa And Bologna”, European Spatial Research and Policy, vol. 22 (2), pp. 57-71.

BONILLA MOYA, M. (2006): "Turismo vivencial: un ejemplo responsable sin ingredientes artificiales", Tecnitur, n 188, pp. 20-23.

BONIFACE, P. (2003): Tasting Tourism: Travelling for Food and Drink. New York, Taylor and Francis Group.

BORDAS, E. (2013): Hacia el turismo de la sociedad de ensueño: nuevas necesidades de mercado. Barcelona, Universitat Oberta de Catalunya. Disponible en htttp://www. uoc.edu/dt/20219/index.

BORGHINI, S., VISCONTI, L. ANDERSON, L. y SHERRY JF. (2010): "Symbiotic Postures of Commercial Advertising and Street Art: Implications for Creativity", Journal of Advertising, vol. 39 (3), pp. 113-126.

CAMPOS, A. C., MENDES, J. y DO VALlE, P. (2016): "Co-creation Experiences: Attention and Memorability", Journal of Travel and Tourism Marketing, vol. 33 (9), pp. $1.309-1.336$

COCKS, C. (2001): Doing the Town: The Rise of Urban Tourism in the United States, 1859-1915. Berkeley, University of California Press.

CRESPI-VALLBONA, M. y RICHARDS, G. (2007): "The Meaning of Cultural Festivals: Stakeholder perspectives in Catalunya", International Journal of Cultural Policy, vol. 13 (1), pp. 103-122.

CRESPI-VALLBONA, M. y DOMÍNGUEZ-PÉREZ, M. (2016): “Los mercados de abastos y las ciudades turísticas", PASOS. Revista de Turismo y Patrimonio Cultural, vol. 14 (2), pp. 401-416

CRESPI-VALLBONA, M., MASCARILLA MIRÓ, O. y VILALTA, R. (2017): “Enología e identidad: maridaje turístico", en Tendencias actuales del turismo. Madrid, Síntesis, pp.145-153.

CRESPI-VALLBONA, M, DOMÍNGUEZ-PÉREZ, M. y MASCARILLA MIRÓ, O. (2019): "Urban food markets and their sustainability: the compatibility of traditional and tourist uses", Current Issues in Tourism, vol. 22 (14), pp. 1.723-1.743

CRESPI-VALLBONA, M. y MASCARILLA-MIRÓ, O. (2018): “La transformación y gentrificación turística del espacio urbano. El caso de la Barceloneta (Barcelona)", EURE. Revista Latinoamericana de Estudios Urbano Regionales, vol. 44 (133), pp. 165-184.

CRESPI-VALLBONA, M. (2021): "Satisfying experiences: guided tours at cultural heritage sites", Journal of Heritage Tourism, vol. 16 (2), pp. 201-217. 
CROMPTON, J. y MCKAY, S. (1997): "Motives of visitors attending festival events", Annals of Tourism Research, vol. 24 (2), pp. 425-439.

CUENCA, M. y PRAT, A. (2012): “Ocio experiencial: antecedentes y características", Arbor. Ciencia, Pensamiento y Cultura, vol. 188 (754), pp. 265-281.

DANN, G. y JACOBSEN, J. (2002): "Leading the tourist by the nose /react-text" en The tourist as a metaphor of the social world. Wallingford, CAB International, pp. 209235.

DE ROJAS, C. Y CAMARERO, C. (2008): "Visitors experience, mood and satisfaction in a heritage context: Evidence from an interpretation center", Tourism Management, vol. 29 (3), pp. 525-537.

DONAIRE, J.A. (2008): "L'efervescencia de la turismofobia", Barcelona Metropolis, $\mathrm{n}^{\circ}$ 72 , pp. 70-75.

EDENSOR, T. (1998, 2008): Tourists at the Taj: Performance and Meaning at a Symbolic Site. New York: Routledge.

FAINSTEIN, S.S. (2001): The city builders: property development in New York and London, 1980-2000. University of Kansas.

FEIFER, M. (1985): Going places. London, Macmillan.

FRIJDA, N.H. (2005): "Emotion experience", Emotion and Cognition, vol. 19, pp. 473494.

GIL, J. y SEQUERA, J. (2018): "Expansión de la ciudad turística y nuevas resistencias. El caso de Airbnb en Madrid", Empiria. Revista de metodología de ciencias sociales, $\mathrm{n}^{\mathrm{o}}$ 41, pp. 15-32.

GLADSTONE, D. y PRÉAU, J. (2008): “Gentrification in tourist cities: Evidence from New Orleans before and after Hurricane Katrina", Housing Policy Debate, vol. 19 (1), pp. 137-175.

GNOTH, J. (1997): “Motivation and expectation", Annals of Tourism, vol. 24 (2), pp. 283-304

GOODSELL, C.T. (2003): "The concept of public space and its democratic manifestations", The American Review of Public Administration, vol. 33 (4), pp. 361-383.

GOOSSENS, C. (2000): “Tourism information and pleasure motivation". Annals of Tourism Research, vol. 27 (2), pp. 301-321.

GOTTDIENER, M. (2000): Life in the Air: Surviving the New Culture of Air Travel. Lanham, Rowman \& Littlefield.

GRAHAM, S. y MARVIN, S. (2001): Splintering Urbanism: Networked Infrastructure, Technological Mobilities and the Urban Condition. London/New York, Routledge.

HALL, C.M. (2011): “A typology of governance and its implications for tourism policy analysis", Journal of Sustainable Tourism, vol. 19 (4-5), pp. 437-457.

HANNIGAN, J. (1998): Fantasy City: Pleasure and Profit in the Postmodern Metropolis. New York, Routledge.

HARVEY, D. (1994): "Flexible Accumulation through Urbanization: Reflections on 'Postmodernism' in the American City" en Post-Fordism: A Reader. Oxford/Cambridge, Blackwell.

HARVEY, D. (2001): Spaces of Capital: Towards a Critical Geography. Nueva York, Routledge. 
HARVEY, D. (2012): Rebel Cities. From the right to the city to the urban revolution. Londres, Verso.

HENDERSON, J.C. (2009): "Food tourism reviewed", Bristish Food Journal, vol. 111 (4), pp. 317-326.

HERBERT, D. (2001): "Literary places, tourism and the heritage experience", Annals of tourism research, vol. 28 (2), pp. 312-333.

HERZER, H. (2008): “Acerca de la gentrificación” en Con el Corazón Mirando al Sur: Transformaciones en el sur de la ciudad de Buenos Aires. Buenos Aires, Espacio, pp. 19-44.

HIRSCHMAN, E. C. y HOLBROOK, M.B. (1982): "Hedonic Consumption: Emerging, Concepts, Methods and Propositions", Journal of Marketing, vol. 46, pp. 92-101.

HOLBROOK, M.B. y HIRSCHMAN, E.C. (1982): "The Experiential Aspects of Consumption: Consumer Fantasies Feelings, and Fun", The Journal of Consumer Research, vol. 9 (2), pp. 132-140.

HOFFMAN, L.M. (2000): “Tourism and the Revitalization of Harlem", Research in Urban Sociology, vol. 5, pp. 207-223.

HOSANY, S. (2012): “Appraisal determinants of tourist emotional responses", Journal of Travel Research, vol. 51 (3), pp. 303-314.

HUGHES, K. (1991): "Tourist satisfaction: A guided "cultural” tour in North Queensland", Australian Psychologist, vol. 26 (3), pp. 166-171.

HUETE, R. y MANTECÓN, A. (2018): "El auge de la turismofobia ¿hipótesis de investigación o ruido ideológico?", PASOS. Revista de Turismo y Patrimonio Cultural, vol. 16 (1), pp. 9-19.

HUNG, W.L., LEE, Y.J. y HUANG, P.H. (2016): "Creative experiences, memorability and revisit intention in creative tourism", Current Issues in Tourism, vol. 19 (8), pp. 763-770.

IYER, P. (2000): The Global Soul: Jet-Lag, Shopping Malls and the Search for Home. London, Bloomsbury.

JAMAL, T., y CAMARGO, B. A. (2018): “Tourism governance and policy: Whither justice?", Tourism Management Perspectives, 25, pp. 205-208.

JUDD, D.R. (2003): "El turismo urbano y la geografia de la ciudad", Eure, vol. 29 (87), pp. 51-62.

KAVARATZIS, M (2004): "From City Marketing to City Branding: Towards a Theoretical Framework for Developing City Brands", Place Branding, vol. 1, pp. 58-73.

KERSTETTER, D.L., CONFER, J.J. y GRAEFE, A.R. (2001): “An exploration of the specialization concept within the context of heritage tourism", Journal of Travel Research, vol. 39 (3), pp. 267-274.

KELLY, M. (1998): Encyclopedia of Aesthetics. New York, Oxford University Press.

KIDD, J. (2016): Museums in the new mediascape: Transmedia, participation, ethics. Londres, Routledge.

LANDRY, C. (2012): The creative city: A toolkit for urban innovators. Londres, Routledge.

LARSEN, J. y MEGED, J. W. (2013): “Tourists co-producing guided tours”, Scandinavian Journal of Hospitality and Tourism, vol. 13 (2), pp. 88-102. 
LLOYD, R. (2000): Grit as Glamour: Neo-Bohemia and Urban Change. Chicago, University of Chicago.

LURY, C. (1997): “The Objects of Travel”, en Touring Cultures: Transformations of Travel and Theory. London/New York, Routledge, pp. 75-95.

MALONE, S., MCCABE, S. y SMITH, A. (2014): "The role of hedonism in ethical tourism". Annals of Tourism Research, vol. 44, pp. 241-254.

MANSILLA, J. (2018): "Vecinos en peligro de extinción. Turismo urbano, movimientos sociales y exclusión socioespacial en Barcelona”, PASOS. Revista de Turismo y Patrimonio Cultural, vol. 16 (2), pp. 279-296.

MARTÍN, J. M. M., MARTÍNEZ, J. M. G. y FERNÁNDEZ, J. A. S. (2018): “An analysis of the factors behind the citizen's attitude of rejection towards tourism in a context of overtourism and economic dependence on this activity", Sustainability, vol. 10 (8), 2851.

MCKERCHER, B. y DU CROS, H., (2002): Cultural tourism: the partnership between tourism and cultural heritage management. New York, Haworth Hospitality Press.

MILANO, C. (2017): “Turismofobia: cuando el turismo entra en la agenda de los movimientos sociales", Marea Urbana. Revista de la Taula Virtual d'Urbanismo de Barcelona, $\mathrm{n}^{\mathrm{o}} 1$, pp. 5-8.

MODLIN J.R, ARNOLD, E. ALDERMAN, D. y GENTRY, G. (2011): “Tour guides as creators of empathy: The role of affective inequality in marginalizing the enslaved at plantation house museums", Tourist Studies, vol. 11 (1), pp. 3-19.

MUÑOZ, F. (2004): “Urbanalización: en el Zoco Global de las lmágenes Urbanas”, Cidades-Comunidades e Territórios, pp. 27-38.

NAVARRO, S., LLINARES, C. y GARZÓN, D. (2016): "Exploring the relationship between cocreation and satisfaction using QCA", Journal of Business Research, vol. 69 (4), pp. 1.336-1.339.

NOVY, J. (2017): 'The Selling (Out) of Berlin and the De- and Re-politicization of Urban Tourism in Europe's "Capital of Cool"' en Protest and Resistance in the Tourist City, London: Routledge, pp. 52-72.

PALOU, S. (2019): "Discursos turístics sobre el paisatge i el patrimoni cultural de Barcelona. Imatges contra la ciutat", Papers, $\mathrm{n}^{\circ}$ 62, pp. 48-58.

PAN, B. y RYAN, C. (2009): “Tourism sense-making: The role of the senses and travel journalism”, Journal of Travel and Tourism Marketing, vol. 26 (7), pp. 625- 639.

PASKALEVA-SHAPIRA, K.A. (2007): "New paradigms in city tourism management: Redefining destination promotion", Journal of Travel Research, vol. 46 (41), pp. 108-114.

PEUAT-Pla Especial Urbanístic d'Allotjaments Turístics, (2017). Barcelona, Ajuntament de Barcelona.

PINE, B.J, y GILMORE, J.H. (1998): "Welcome to the Experience Economy", Harvard Business Review, vol. 76 (4), pp. 97-105.

POSTMA, A. y SCHMUECKER, D. (2017): "Understanding and overcoming negative impacts of tourism in city destinations: conceptual model and strategic framework", Journal of Tourism Futures, vol. 3 (2), pp. 144-156.

PREBENSEN, N.K., KIM, H. y UYSAL, M.S. (2016). "Co-creation as moderator between the experience value and satisfaction relationship", Journal of Travel Research, vol. 5 (7), pp. 934-945 
PRESENZA, A., SHEEHAN, L. y RITCHIE, J.B. (2005): "Towards a model of the roles and activities of destination management organizations", Journal of Hospitality, Tourism and Leisure Science, vol. 3 (1), pp. 1-16.

QUAGLIERI DOMÍNGUEZ, A. y SCARNATO, A. (2017): "The Barrio Chino as last frontier: the penetration of everyday tourism in the dodgy heart of the Raval", en Tourism and Gentrification in Contemporary Metropolises. New York, Routledge: New York, pp. 107-133.

RITCHIE, J.B. y CROUCH, G.I. (2003): The competitive destination: A sustainable tourism perspective. Cabi.

RIVERA MATEOS, M. (2013): "El turismo experiencial como forma de turismo responsable e intercultural", en Relaciones interculturales en la diversidad, Cátedra Intercultural, pp. 199-217.

ROSAS MANTECÓN, A. (2013): “¿Patrimonio para la inclusión? Hacia un nuevo modelo de turismo cultural”, Cuadernos de Patrimonio Cultural y Turismo, no 19, pp. 51-59.

SASSEN, S. (1994): Cities in a World Economy. London, Pine Forge Press.

SHARPLEY, R. (2014): "Host perceptions of tourism: A review of the research", Tourism Management, vol. 42, pp. 37-49.

SIMS, R. (2009): "Food, place and authenticity: local food and the sustainable tourism experience", Journal of Sustainable Tourism, vol. 17 (3), pp. 321-336.

SORANDO, D. y ARDURA, A. (2016): First we take Manhattan. Madrid, La Catarata.

STAMBOULIS, Y. y SKAYANNIS, P. (2003): "Innovation strategies and technology for experience-based tourism", Tourism management, vol. 24 (1), pp. 35-43.

TROYE, S. y SUPPHELLEN, M. (2012): “Consumer participation in coproduction: 'I made it myself' effects on consumers' sensory perceptions and evaluations of outcome and input product", Journal of Marketing, vol. 76 (2), pp. 33-46

TSAI, C.T. (2016): "Memorable Tourist Experiences and Place Attachment When Consuming Local Food", International Journal of Tourism Research, vol. 18 (6), pp. 536-548

URRY, J. (2002): The Tourist Gaze: Leisure and Travel in Contemporary Societies. London, Sage Publications.

URRY, J. y LARSEN, J. (2011): The tourism gaze, 3.0. London, Sage.

VAN DER ZEE, E., GERRETS, A. M., y VANNESTE, D. (2017): "Complexity in the governance of tourism networks: Balancing between external pressure and internal expectations", Journal of Destination Marketing \& Management, vol. 6 (4), pp. 296-308.

VÁSQUEZ CÁRDENAS, A.V. (2013): "Las políticas públicas urbanas como proceso plural. Enfoques de política urbana y gobernanza urbana", Estudios Políticos, n 42 , pp. 218-241.

VELASCO GONZÁLEZ, M. (2013): “Gestión pública del turismo. La Gobernanza” en Gestión estratégica sostenible de destinos turísticos. Universidad Internacional de Andalucía, pp. 469-520.

VOGELER, C. y HERNÁNDEZ, E. (2002): El Mercado Turístico: estructura, operaciones y procesos de producción. Madrid, Centro de Estudios Ramón Areces.

VOLGGER, M. y PECHLANER, H. (2014): "Requirements for destination management organizations in destination governance: Understanding DMO success", Tourism Management, vol. 41, pp. 64-75. 
WANG, N. (2005): "Urbanscape as attraction-the case Guangzhou" en Seductions of place: Geographical perspectives on globalization and touristed landscapes. London, Routledge. pp, 135-147.

WEARING, S., STEVENSON, D. y YOUNG, T. (2010): Tourist cultures: identity, place and the traveller. Los Angeles, Sage.

WILLSON, G.B. y MCINTOSH, A. (2008): "Heritage Buildings and Tourism: An Experiential View", Journal of Heritage Tourism, vol. 2 (2), pp. 75-93.

WISE, N. (2016): "Outlining triple bottom line contexts in urban tourism regeneration", Cities, vol. 53, pp. 30-34.

YI,Y. y GONG, T. (2013): "Customer value co-creation behavior: Scale development and validation”, Journal of Business Research, vol. 66 (9), pp. 1.279-1.284. 